\title{
El poder de contar y el paraíso perdido. Polémicas públicas y construcción colectiva de la memoria en España
}

\author{
The Power of Narrating and the Lost Paradise. \\ Public polemics and the collective building of the past in Spain
}

\author{
Sebastiaan FABER \\ Oberlin College \\ sebastiaan.faber@oberlin.edu \\ Pablo SÁnchez León \\ Universidad del País Vasco \\ psleon@gmail.com \\ Jesús Izquierdo Martín \\ Universidad Autónoma de Madrid \\ jesus.izquierdo@uam.es
}

Recibido: 10.11 .2010

Aprobado definitivamente: 03.06.2011

\section{RESUMEN}

Durante la pasada década se ha incrementado el interés de los medios de comunicación y de la sociedad civil española por la "memoria histórica", interés que se ha puesto de manifiesto, entre otras cosas, en algunos debates relacionados con el pasado reciente (1931-1981). En estos debates han participado historiadores profesionales y otros actores sociales, desde escritores y directores de cine a ciudadanos activistas. El presente ensayo analiza una de las interminables polémicas que tuvo lugar en la primavera de 2010 con el fin de destacar algunos problemas estructurales, especialmente la tendencia de parte de los creadores de opinión - incluidos historiadores académicos que actúan como figuras mediáticas - a monopolizar el derecho de "contar el pasado" a partir de la ingenua reivindicación de que el conocimiento histórico profesional procede de la verdad factual. La primera parte del ensayo aborda el papel de los historiadores y la historia académica en los medios. La segunda analiza la posición etnocéntrica que adoptan algunos intelectuales liberales españoles cuando se enfrentan a la internacionalización de la justicia transicional. La tercera parte critica la manera en la que los "intelectuales mediáticos" en España impiden la discusión verdaderamente democrática del pasado colectivo.

Palabras Clave: Memoria histórica, pasado reciente, conocimiento histórico, historiadores, intelectuales, medios de comunicación, ciudadanía, democracia. 


\begin{abstract}
The past decade has seen an increasing interest on the part of the Spanish media and civil society in "historical memory", marked, among other things, by a number of public debates on issues related to recent Spanish history (1931-1981). In these debates, academic historians have participated alongside other social actors, ranging from writers and filmmakers to citizen activists. The following essay analyzes one such drawn-out polemic that took place in the spring of 2010, in order to point to a series of structural problems, particularly the tendency on the part of opinion makers - including academic historians writing as media personalities - to monopolize the right to "tell the story of the past," a claim based on a naïve invocation of scholarly historical knowledge as factual truth. The essay's first part addresses the role of historians and academic history in the media. The second part analyzes the ethnocentric position of some Spanish liberal intellectuals faced with the internationalization of transitional justice. The third part takes a critical look at the way that Spain's "media intellectuals" help to prevent a truly democratic mode of discussing the collective past.
\end{abstract}

KeYwords: Historical Memory, Recent Past, Historical Knowledge, Historians, Intellectuals, Media, Citizenship, Democracy

\title{
SUMARIO
}

1. Historia, memoria, violencia: un debate a la española. 2. Usos y abusos en una batalla más por el poder de contar. 3. El supuesto de la excepcionalidad española en la era de la globalización. 4. Intelectuales mediáticos, historiadores y "memoria histórica". 5. De paraísos e infiernos. 


\section{HISTORIA, MEMORIA, VIOLENCIA: UN DEBATE A LA ESPAÑOLA}

Desde hace al menos una década, los medios de comunicación españoles distribuyen información bajo el membrete de "memoria histórica" y acogen con regularidad polémicas relacionadas con el pasado reciente, especialmente sobre los cincuenta años transcurridos entre la proclamación de la Segunda República en 1931 y el intento de golpe de Estado de 1981, un período de creación y supresión de derechos ciudadanos jalonado de acontecimientos traumáticos. Violencia, historia y memoria del pasado reciente son en suma desde comienzos del siglo XXI temas de actualidad y controversia no sólo entre especialistas, sino también entre ciudadanos no versados en historiografía: prensa y programas televisivos, así como páginas de Internet y blogs recogen opiniones y argumentaciones de especialistas universitarios junto con un elenco muy variado que incluye desde literatos y cineastas hasta militantes de organizaciones civiles, pasando por formadores de opinión, líderes políticos y ciudadanos de a pie.

Basta una breve ojeada a la ingente producción de discurso público en torno a la memoria histórica de los últimos diez años para entender que, en la práctica, la controversia se halla desde hace tiempo fuera del control de las instituciones - académicas y estatales- que se han solido arrogar el monopolio del poder de contar el pasado. No son en efecto los historiadores profesionales quienes marcan las líneas de discusión pública; tampoco sus investigaciones establecen ya los consensos dominantes. Incluso es posible argumentar que las relaciones se han invertido: en buena medida el mundo académico ha tenido que dar entrada a enfoques, reflexiones y relatos acerca de la historia y la memoria procedentes de la esfera de opinión pública. ${ }^{1}$ Contemplado así, cualquier intento de ofrecer un estado de la cuestión de las relaciones entre historia, memoria y violencia en la España actual que no tenga en consideración las polémicas públicas produciría un mapa incompleto, distorsionado y engañoso de sus fuentes de inspiración y líneas de orientación dominantes.

Ahora bien, esto no implica que exista un trasvase fluido de ida y vuelta entre las posturas y conclusiones de las polémicas públicas y los consensos intra-académicos en materia de historia, memoria y violencia. Más bien al contrario: en términos generales las polémicas sobre "memoria histórica" han producido más bien incomunicación, cuando no desencuentro, entre historiadores académicos y ciudadanos motivados, afectados o movilizados, lo que ha venido redundando en una notable escasez de diálogo y debate público sobre el conocimiento del pasado reciente. ${ }^{2}$ Por su parte, el estudio de la vio-

\footnotetext{
${ }^{1}$ Entre 1996 y 1999, la iniciativa acerca de estos asuntos procedió del mundo académico, de lo cual son buena muestra las obras de Aguilar (1996) y Juliá (1999). Sin embargo, coincidiendo con la publicación de la obra de Silva y Macías (2003), los flujos parecen haber cambiado de sentido. Un ejemplo pionero fue la divulgación mediática en 2002 del documental Els nens perduts del franquisme el cual, aunque contó con el asesoramiento del historiador Ricard Vinyes, no formó parte de los resultados de una línea de investigación académica preestablecida sino de la cooperación ad hoc entre Vinyes, una periodista (Montse Armengou) y un realizador de cine (Ricard Belis). Véase Vinyes, Armengou y Belis (2003). Seguimos en esto el esbozo de reconstrucción de Ruiz Torres (2007); véase además Juliá (2009). Siete años después, en 2009, la apertura por el juez Baltasar Garzón de diligencias para esclarecer las causas de la muerte de civiles inhumados en numerosas fosas a lo largo del territorio nacional, ha puesto de manifiesto que la iniciativa civil ajena al mundo académico se adentra ya incluso por territorios tradicionalmente exclusivos de los expertos; en este caso, cuestionando los datos sobre víctimas de la guerra de 1936 recogidos en Juliá (1999). Por su parte, en el caso del llamado "revisionismo" representado por la obra de Pío Moa, la recepción académica ha sido extremadamente tardía. Compárense los años de publicación de los dos textos más divulgados de este autor (1999 y 2003), con los de obras centradas en su crítica: Espinosa Maestre (2005), Reig Tapia (2006), Serna (2006-2007), y Moradiellos (2007). Los especialistas han justificado su desinterés tanto por este revisionismo cuanto por las evidencias y estimaciones acerca de las víctimas de la guerra argumentando que no proceden de historiadores profesionales o de datos de archivo. Véase, por ejemplo, Juliá (2003). La influencia de las polémicas públicas sobre las relaciones entre profesionales es con todo notoria. Véase el duro intercambio de acusaciones y reproches entre Santos Juliá, Francisco Espinosa, Pedro Ruiz Torres y los editores de Hispania Nova en el num. 7 de esa revista (http://www. hispanianova.rediris.es) en torno de una polémica sobre memoria y olvido de la violencia durante la transición

${ }^{2}$ La frase sentenciadora de Santos Juliá - "la memoria es una cosa y la historia es otra" - refleja la opinión de toda una corriente de historiadores profesionales que desde el principio ha mostrado una actitud paternalista y desdeñosa cuando no hostil hacia las movilizaciones ciudadanas en relación con la recuperación del pasado traumático. Véase la entrevista de Leonor García a Juliá en la página web de la UNED (http://portal.uned.es/portal/page? pageid=93,540478\&_dad=portal\&_schema=PORTAL). Otras obras de Juliá que insisten en lo mismo son (2003, 2006 a y b), algunas de ellas ahora recogidas en Juliá (2010). Por el lado contrario del es-
} 
lencia de inspiración ideológica ejercida en el siglo $\mathrm{XX}$ sobre individuos o grupos civiles no ha figurado hasta hace poco entre las prioridades de los investigadores españoles, de manera que la producción académica no ha podido servir en este caso de referente para vertebrar las polémicas públicas. ${ }^{3}$ A ello hay que añadir un importante rasgo del contexto institucional: entre los historiadores profesionales españoles, los debates razonados entre colegas académicos - por no decir entre estudiantes y profesores- no suelen funcionar como instrumento de mejora y reorientación de las agendas de investigación (Castro y Martínez Bermejo, 2008). Al igual que otros anteriores, los intercambios públicos centrados en el pasado reciente se han venido topando, pues, con evidentes bloqueos en el terreno de la producción y expansión del conocimiento, quedando marcados por tendencias a la descalificación personal como forma de interpelación del contrario intelectual, a la producción de ortodoxia como fin de las diatribas $\mathrm{y}$, en la práctica, a la infravaloración del diálogo como medio indispensable para la construcción de consensos sobre el pasado y su conocimiento.

Estamos, pues, ante un típico debate "a la española" cuyos rasgos se reproducen a ambos lado de la frontera entre el mundo académico y el público; podría pensarse entonces que carece de singularidad y por ende de interés. En el caso de la polémica pública que vamos a analizar, no obstante, interviene un elemento específico que justifica su seguimiento como parte de los debates académicos sobre historia, memoria y violencia: la doble condición encarnada en los últimos años por algunos historiadores como expertos profesionales, de un lado, y como formadores de opinión pública, de otro, normalmente desde la tribuna de medios de comunicación concretos (Faber, 2007). Esta dualidad de roles no debe confundirse con un mismo tipo de intervención - en tanto que expertos - en ámbitos diferentes, unos académicos y otros no. Al contrario: como intentaremos mostrar en lo que sigue, lo que revela es un divorcio entre la dedicación profesional y una actividad pública a menudo ajena a su especialización. Esta segunda dimensión converge con la que vienen desarrollando por su parte otros formadores de opinión - novelistas, cineastas, periodistas...- que, sin ser historiadores profesionales, se dedican también a ofrecer sus juicios e interpretaciones sobre el pasado reciente. Pese a las diferencias de formación, recelos corporativos y discrepancias de opinión, la actuación de estos dos grupos de intelectuales mediáticos produce toda una serie de efectos sobre la calidad de la cultura política democrática y el conocimiento sobre el pasado reciente de los ciudadanos españoles, efectos que merecen ser analizados críticamente.

Este ensayo pretende poner de manifiesto algunos de los problemas que para los ciudadanos de un orden democrático pluralista suscitan las diatribas entre formadores de opinión - expertos o no- en temas relacionados con el pasado y su conocimiento. Como se tratará de mostrar, la gran mayoría de los intelectuales mediáticos se arrogan — no necesariamente de forma consciente- el derecho de "contar el pasado" a unos ciudadanos a los que tratan como meros receptores pasivos de un conocimiento que aquellos se esfuerzan por presentar como objetivo, puramente factual y ajeno a todo prejuicio en relación con el presente. Dicha actitud excluyente se manifiesta de forma especial cuando se abordan episodios fuertemente marcados en la memoria colectiva por su elevado coste en términos de violencia y trauma.

En lugar de contribuir a aumentar la conciencia histórica de los ciudadanos, en general los intelectuales mediáticos se emplean a fondo en descalificarse entre ellos, presentándose como poseedores de la verdad histórica y vertiendo sobre el contrario

pectro se situaría Ricard Vinyes (Vinyes, 2010), cuya representatividad dentro del cuerpo de historiadores españoles es con todo muy inferior a la de Juliá. Una postura intermedia aunque tampoco mayoritaria viene a estar representada por Julián Casanova (2007).

${ }^{3}$ Esto no significa que no dispongamos de trabajos sobre violencia durante el pasado reciente hispano escritas en castellano u otras lenguas. No obstante, incluso entre los especialistas en violencia en la España contemporánea se admite que el empuje de las polémicas públicas por la memoria ha sido determinante en la consolidación y expansión del tema como campo de investigación académica. Así, aunque hubiera ya alcanzado una suerte de mayoría de edad ya en los años noventa, el movimiento civil de comienzos del siglo XXI ha "disparado exponencialmente el interés por la violencia — sobre todo la franquista—y lo ha llevado no sólo a nutrir aún más la actividad investigadora sino también a una explosión de atención mediática, temas, títulos y soportes que desbordan con mucho la literatura histórica" (Ledesma, 2009: 166). 
descalificaciones sobre la supuesta inferioridad de su argumentación. Con frecuencia estas descalificaciones invocan una distinción conceptual entre historia (que se supone objetiva por basada en una investigación científica) y memoria (presentada como subjetiva y moldeada por intereses políticos, comerciales, etc.), cuya implícita jerarquía valorativa es fácil de captar (Faber, 2007). En realidad, sin embargo, se trata de una distinción poco reflexiva: apenas teorizada, su empleo resulta casi puramente retórico, con potenciales derivas demagógicas. Cabe además sospechar que la descalificación de ciertos tipos de conocimiento del pasado como mera "memoria" esconde una aspiración de oligopolio sobre el poder de contar la historia del otro, y convertirla además en historia definitiva. El resultado es paradójico: en vez de contribuir a subrayar el sesgo contingente y temporal —en una palabra, histórico- de nuestras representaciones del pasado y las creencias que las informan, facilitando así el diálogo público y cívico (Palti, 2008), los intelectuales mediáticos contribuyen decididamente a simplificar la experiencia de los ciudadanos, creando estereotipos afincados en un pasado naturalizado a partir del cual se vuelve difícil repensar colectiva y críticamente no sólo ese pasado, sino también el presente y el futuro.

Con objeto de dar cuenta de esa ambición oligopólica del contar el pasado y reflexionar sobre el malestar que genera en una sociedad pluralista como la española, hemos optado por reflexionar a partir de una batalla mediática concreta ocurrida recientemente en las páginas de la prensa de gran tirada y de Internet entre aproximadamente el 14 de abril y el 18 de julio de $2010{ }^{4}$

La primera parte de este texto aborda la controversia entre intelectuales y "opinadores" sobre la genealogía política de la España postfranquista con objeto de analizar el modo en que el conocimiento histórico suele aparecer en este país en la esfera pública, a saber, reducido a una colección de "datos" que reciben autorización por haber sido recabados por expertos historiadores. La segunda parte se concentra en la intervención concreta de dos intelectuales mediáticos que han participado en el debate adoptando una postura etnocéntrica incompatible con enfoques basados en valores y conceptos universales como los Derechos Humanos. El objetivo aquí es argumentar que, frente al militante empirismo que subyace a toda la controversia, todo conocimiento sobre el pasado adopta siempre la forma de una interpretación de acontecimientos cuyos marcos de significado están predeterminados por el contexto social en el que ésta es elaborada. Por último, la tercera parte aborda cómo, cuando habla del pasado reciente, el intelectual mediático español incumple su función tradicional de observador distanciado de sus marcos provincianos de interpretación, al tiempo que, al adoptar un ensimismamiento cientificista, se inhabilita para intervenir públicamente de manera cívica en un asunto que, como el del pasado violento y sus traumas, reclama ser afrontado con la participación de todos los ciudadanos concernidos, interesados o afectados.

\section{USOS Y ABUSOS EN UNA BATALLA MÁS POR EL PODER DE CONTAR}

La controversia pública que tuvo lugar en los medios durante la primavera y verano de 2010 se desenvolvió a lo largo de dos líneas principales: el debate sobre los orígenes históricos de la democracia de 1978 y la lucha por el poder de narrar "la verdad" acerca del pasado. La primera arranca de una pregunta en apariencia para expertos, y sobre la cual en cualquier otro contexto se habría puesto de manifiesto un consenso preestablecido suficiente y prolongado: ¿dónde se asientan las raíces históricas de la legitimidad de la democracia de 1978? Aunque formalmente empírica, está lejos de tratarse de una pregunta abierta. En el contexto en el que tuvo lugar la polémica, la respuesta presuponía una disyuntiva

\footnotetext{
${ }^{4}$ En total hemos utilizado hasta 23 artículos procedentes de medios escritos e Internet entre estas dos fechas (ver el apartado en Referencias). Además de conmemorar respectivamente el 79 aniversario de la proclamación de la Segunda República y el 74 aniversario del golpe de Estado de Franco, dichas fechas resultan jalones pertinentes para el caso estudiado. La primera de ellas señala el inicio de las movilizaciones ciudadanas en contra del procesamiento del juez Baltasar Garzón y que, bajo el lema de "No a la impunidad" culminaron en una importante manifestación en las principales ciudades españolas el sábado 22 de abril; la segunda fecha coincide grosso modo con la llegada del período estival en la actividad periodística, en la que suelen descender las contribuciones polémicas y se diluyen o detienen los debates en curso.
} 
excluyente: la tradición en que se apoya la democracia postfranquista es, o bien la de la Segunda República de 1931, o bien la de la cultura antifranquista desarrollada a partir de los años 50 .

Conviene subrayar que la cuestión no surge, con todo, del interior de las universidades, sino a rebufo de las polémicas suscitadas por el llamado "movimiento de la memoria". En efecto, en gran medida gracias a la movilización ciudadana ha saltado a la esfera pública una interpretación del pasado reciente que reivindica abiertamente la experiencia de la Segunda República como tradición de la que bebe - o debería beber - la democracia actual. En el fondo, las intervenciones públicas de los intelectuales mediáticos que aquí tratamos fueron intentos de autorizar o desautorizar este emergente relato de orígenes que los historiadores de la España postfranquista identificados con el ethos de la Transición se han esforzado en eludir (Aguilar, 1999).

En la polémica que nos ocupa, entre los polemistas que desautorizaron la conexión entre el siglo XXI y el republicanismo de los años treinta destacan Santos Juliá, Gregorio Marañón, Pío Moa y José Juan Toharia; la posición contraria fue defendida principalmente por Almudena Grandes, Javier Cercas, Carlos Carrillo, Aitor Carr y Josep Fontana. En principio podría presuponerse que el equilibrio en el número de plumas garantizaría un debate en igualdad de condiciones. Mas no fue así, pues el grupo representado por Juliá y Marañón contó con una importante ventaja: mientras los académicos españoles han sido poco sensibles al estudio de la cultura política de los años 30, historiadores y sociólogos han venido en cambio en los últimos decenios edificando un marco compartido de lenguaje que da sentido a lo sucedido en España entre 1956 y 1976-1978. A partir de dicho marco se han elaborado las narrativas dominantes sobre la transición a la democracia, que en general subrayan el surgimiento de una cultura de desafección a la dictadura franquista.
La falta de una tradición narrativa similarmente institucionalizada supone una clara desventaja para los defensores de la idea de que la actual democracia española es heredera del legado republicano. En la polémica que describimos, esta carencia se manifestó, entre otras cosas, en argumentaciones que, no contando con el apoyo de una tradición narrativa con anclajes teóricos sólidos, se muestran poco coherentes o extemporáneas. Así, en sus intervenciones, Javier Cercas reivindicó la herencia de la República estableciendo no obstante para ello una separación entre principios morales y principios políticos que, aunque remite a Ortega y antes a Weber, no ha solido ser utilizada para caracterizar la encrucijada de los ciudadanos españoles de los años $30 .^{5}$ Almudena Grandes, por su parte, también tuvo que ceñirse a argumentos morales, en su caso valiéndose de un poeta, Luis Cernuda, como avalista de su postura favorable a la República, además de desautorizar éticamente al contrario - Joaquín Leguina - acusándolo de sustentar su opinión en una errática e inconsistente trayectoria política personal. ${ }^{6}$

La otra postura - defendida con escasas diferencias por Juliá, Marañón, Leguina y otros - se benefició en cambio de un marco discursivo preexistente inserto en la memoria colectiva de los ciudadanos del siglo XXI y cuyo eje común es que la democracia postfranquista habría nacido del diálogo que desde los años 50 entablaron las partes divididas por la guerra de 1936-1939, quedando plasmado finalmente en la Ley de Amnistía de 1977 y en la Constitución de 1978. Que se trata de una narrativa dominante lo pone de manifiesto el hecho de que quienes defendieron esta posición en la polémica no se tomaron la molestia de avalarla con los resultados de investigaciones específicas. Lo que esgrimieron en su lugar fueron una serie de a priori compartidos y heredados: en especial, la idea de que la democracia actual no puede tener sus orígenes en la Segunda República debido a la violencia constitutiva de ésta.

\footnotetext{
${ }^{5}$ En cambio sí lo ha sido abundantemente al abordar la transición postfranquista. De hecho le sirve al propio Cercas como principio interpretativo en Anatomía de un instante (2009) su ensayo-ficción sobre el 23-F, en particular a la hora de juzgar la conducta de figuras como Suárez y Carrillo. En la polémica que comentamos afirmó que "lo único que se le debe exigir a la derecha es que en este caso distinga entre moral y política, y que, sin quitarles necesariamente la razón moral a sus antepasados, les quite la razón política". Ha vuelto a insistir más tarde en el mismo presupuesto en su artículo "No es lo mismo claro que simple", EL PAís SEMANAL, 22-08-2010.

${ }^{6}$ Para desacreditar a Leguina, la escritora contrastó la opinión anterior de éste sobre el tema, y concluyó: “Entre 1992 y 2010 caben 18 años, sucesivas derrotas políticas y la gratitud a una presidenta autonómica, Esperanza Aguirre, que le ha arreglado un puestecito".
} 
Así, por ejemplo, para Joaquín Leguina "[1]a inmensa mayoría de la derecha española [había renegado] de la democracia durante la República y, desde luego, durante la guerra" y "la izquierda, en gran parte, [había hecho] lo mismo".

Pese a su hegemonía, las argumentaciones ad hoc derivadas del marco discursivo dominante no están tampoco libres de puntos débiles y aporías, sobre todo cuando se quedan en una evaluación más bien moral que analítica de la opción contraria. Es lo que sucedió en esta diatriba al estar centrada en una cuestión que, como la violencia, resulta tan sensible entre el público de la España postfranquista. Uno de sus puntos flacos a este respecto es de mínimo contraste empírico: no resulta muy riguroso censurar la violencia en la etapa republicana de los años treinta y en cambio omitir la producida también durante la crisis de la dictadura y transición a la democracia, que incluye entre sus datos iniciales todo un "magnicidio" como el del presidente del gobierno Carrero Blanco. ${ }^{7}$ Pero el problema mayor se manifestó en el nivel del relato concreto urdido para deslegitimar la opción contraria. Éste resultó ambiguo por su posible vinculación con otros relatos heredados que siguen marcando la memoria colectiva de los españoles hacia el pasado reciente. No es nuestro cometido aquí evaluar si la relación establecida por Juliá, Leguina y otros entre Segunda República y violencia contenía o no ecos de la posición que la derecha adoptó al respecto ya en los años treinta y que el franquismo elevó a dogma institucional. Lo cierto es que, siendo incuestionable que la década de los 30 fue violenta en España, definir dicha violencia como constitutiva del orden democrático republicano - o cuando menos de unos grupos sociales y políticos a los que se supone una enorme capacidad independiente de desestabilización - es hoy día una interpretación que puede ser legítimamente leída como afín a la de la derecha (neo)franquista. En esta dirección se produjo la intervención de Josep Fontana en la disputa, que fue por el lado opuesto avalada por Pío Moa al ponderar por su parte la postura de Juliá.

El problema de fondo que pone de manifiesto esta situación no es otro que el de la cautela hermenéutica que conviene adoptar a la hora de interpretar las huellas del pasado a partir del momento pre- sente. Los participantes en la polémica esgrimieron sus opiniones sobre lo que sucedió en los años 30 y en los 50 por medio de enunciados abstractos tales como "democracia", "derecho", "nación española", "libertad", "igualdad", "revolución", etc. Ahora bien, ¿acaso podemos hacer caso omiso de los cambios de significado experimentados históricamente por estos referentes en los que se apoya la actual legitimidad democrática postfranquista? ¿Cómo ignorar la larga duración de la dictadura y su capacidad para alterar de manera profunda e indeleble no sólo las estructuras económicas y sociales, sino también las semánticas preexistentes? Para evitar parecer que se retoman posiciones de hace más de medio siglo y entablar en su lugar un diálogo constructivo sobre las bases históricas de la actual legitimidad democrática parece necesario establecer de antemano con un mínimo de rigor no sólo las continuidades sino también las cesuras de significado entre el lenguaje del presente y aquél con el que nuestros antepasados pensaron el mundo y actuaron sobre él (Izquierdo y Sánchez León, 2006: 143-226).

Lo cierto, sin embargo, es que este asunto de los cambios en los referentes lingüísticos no ha sido apenas abordado por los académicos españoles desde el establecimiento de la democracia en España: brillan por su ausencia estudios al respecto procedentes de filólogos, filósofos, sociólogos o historiadores culturales. Ni siquiera la disyuntiva abordada en la polémica mediática que venimos siguiendo ha figurado como prioridad entre historiadores y científicos sociales: aunque existen abundantes investigaciones históricas sobre la democracia y la ciudadanía en los años treinta, así como enfoques analíticos que abordaban desde las ciencias sociales los fundamentos de la legitimidad postfranquista, nunca ha habido una agenda de investigación y reflexión dedicada a explorar sistemáticamente y de manera comparada la relación entre la actual democracia española y posibles tradiciones institucionales y culturales concurrentes susceptibles de figurar como base histórica de su legitimidad.

Esto afecta al propio concepto de violencia y los calificativos que ha recibido entre algunos participantes en esta polémica. Quienes rechazan la idea de que la democracia española de hoy pueda ser

${ }^{7}$ En su reciente trabajo Sánchez Soler (2010) recaba información sobre otras 2.663 víctimas mortales y heridos entre 1975 y 1983. 
heredera del legado republicano de los años treinta coincidieron en culpar de la violencia de entonces a una izquierda caracterizada como en deriva "revolucionaria". Santos Juliá fue quien con mayor claridad lo expresó, al escribir que "esos crímenes obedecieron a una lógica propia, reiteradamente publicitada desde discursos de líderes anarquistas, comunistas y socialistas, repetidos cada vez que se cometía un crimen masivo: que era preciso destruir desde la raíz el viejo mundo, prender fuego a sus símbolos y proceder a la limpieza de sus representantes".

No hay duda de que durante la República existieron grupos que se autodenominaban revolucionarios, algunos de los cuales ejercían la violencia de diversas maneras. Pero esto no significa que hubiera entonces un consenso como el que Juliá, Leguina y otros parecen asumir acerca de la vinculación intrínseca entre cambio radical del orden social y violencia indiscriminada. ${ }^{8}$ Su argumentación se efectúa sin tomar distancia de un contexto - el actual- sobre el que pesa la herencia del final de la Guerra Fría, que ha venido a escindir abiertamente como alternativas la democracia y la violencia revolucionaria. ${ }^{9}$ Una visión en cambio más histórica sobre la democracia sacaría sin duda a relucir que el establecimiento de sistemas democráticos ha venido casi siempre acompañado del concurso de utopías que aspiran a ir bastante más lejos de un mero sistema político representativo, y cuyos líderes o bases en determinados contextos concluyen que sin el recurso a la violencia desde la sociedad civil organizada es imposible debilitar de manera determinante las instituciones que impiden el avance de las libertades.
Para afinar en este terreno hubiera hecho falta no obstante una discusión sobre la cambiante relación entre revolución, violencia y democracia, aplicable no sólo a la España de los años treinta sino también en cierta medida a la de los setenta y en general a toda la modernidad occidental y global hasta el presente. En ausencia de ello, la disputa aparentemente empírica disfraza lo que en realidad es una disputa política. Ahora bien, si ese disfraz se muestra eficaz ello se debe a que los intelectuales mediáticos se presentan en los medios de comunicación como profesionales que parecen contemplar el pasado desde ninguna parte, desde la neutra objetividad que otorga el "método histórico" practicado o imputado a sus avalistas, a modo de mágico artefacto que al parecer permite distanciarse del presente para mirar el ayer "tal y como fue".

Llegamos así a la segunda gran línea que subyace a la polémica: la lucha por apropiarse de la verdad, una verdad entendida como algo irrefutable. Términos como "la verdad de una puñetera vez", "la puñetera verdad", "establecer la verdad", "la verdadera diferencia" o la "falsedad" sobre esto o aquello recorren los distintos artículos en un tono vehemente marcado por el dogmatismo o una lógica amigoenemigo que privilegia las alianzas o enemistades personales sobre los argumentos y el diálogo razonado. De hecho, curiosamente cuando los polemistas más invocaban la verdad, más virulento resultaba el tono del debate. ${ }^{10}$

Esta manera de proceder parece reflejar que en última instancia estos formadores de opinión no aspiraban a contar nada sobre la guerra y el franquis-

\footnotetext{
${ }^{8}$ Por poner un contraejemplo procedente del mismo contexto, el propio Walter Benjamin cuestionaba en los años veinte que la "huelga general proletaria", que "se impone como única tarea la destrucción del Estado" sea una forma de interrupción del trabajo "violenta", pues no espera concesiones externas o modificación de las condiciones de trabajo salvo en una forma nueva de organización de la producción no impuesta ya por el estado: “A esta concepción profunda, moral y claramente revolucionaria no se le puede oponer un razonamiento destinado a calificar como violencia esta huelga general a causa de sus eventuales consecuencias catastróficas". Véase Benjamin, "Para una crítica de la violencia" [1919], www.philosophia.cl, p. 12.6 Para desacreditar a Leguina, la escritora contrastó la opinión anterior de éste sobre el tema, y concluyó: "Entre 1992 y 2010 caben 18 años, sucesivas derrotas políticas y la gratitud a una presidenta autonómica, Esperanza Aguirre, que le ha arreglado un puestecito".

${ }^{9}$ En el caso concreto de la postura de Santos Juliá, el prejuicio se hace evidente cuando opina que si el bando pro-republicano hubiera durante la guerra de 1936-1939 ganado terreno al enemigo, al parecer habría allí seguido "matando a mansalva, como en las primeras semanas de la revolución". La opinión es legítima, pero inconsistente, no ya por tratarse de un contrafactual incomprobable, sino porque se vuelve contra el corazón mismo de la argumentación de su autor, quien previamente ha definido la violencia revolucionaria como aquella que va dirigida contra los "representantes" del viejo orden. Dado que no es posible esgrimir ninguna teoría que identifique a los representantes del viejo orden en general como un grupo social de gran tamaño — sólo lo cual justificaría asesinatos "a mansalva" - la opinión expresa una prejuiciosa identificación entre violencia revolucionaria y crimen masivo. Una crítica a este reduccionismo en Haynes (1998), quien reenvía a su vez al capítulo final de Los orígenes sociales de la dictadura y la democracia, en el que Barrington Moore cierra su libro fundacional de la sociología histórica recordando a los futuros investigadores, como Juliá,
} 
mo que no pasase por ofrecer en realidad la historia del otro, del contrario, un contrincante que, siendo del presente, es discursivamente trasladado al pasado para servir de peón en la lucha que no es otra que la de descalificar al contrario ideológico. De ese "otro" estos intelectuales columnistas han ofrecido un relato urdido a base de juicios valorativos, de ahí que tuviera que presentarse como una historia definitiva y única.

Leer así la polémica que protagonizaron viene a ser como asistir a un "Juicio Final". De todo ello, lo que aquí nos interesa es que el conocimiento histórico juega en dicho juicio un papel retórico protagonista y decisivo. Así, aunque en este debate la participación de historiadores propiamente dichos fue relativamente escasa, su presencia ha de verse como determinante debido a que casi todos los intervinientes apelan a éstos de forma indirecta y colectiva como avalistas que proporcionan el respaldo epistemológico que los creadores de opinión necesitan para afianzar su "verdad", presentada a su vez como única, excluyente y fundamentada en los datos y los métodos de la historia profesional. Sólo recurriendo retóricamente a ella se pueden ofrecer como verdades definitivas lo que no dejan de ser opiniones subjetivas. Almudena Grandes, por ejemplo, apuntaló su opinión de que "[n]ingún autor republicano español ha dejado de acusar la vergüenza de las checas", afirmando que una vez retomado el poder por el gobierno éstas "se cerraron y las patrullas pasaron a ser, al menos oficialmente, perseguidas por la ley. Esto es tan bien conocido, está tan exhaustivamente documentado y explicado, tantos historiadores lo han dado ya por tema concluido, que no debería ser necesario mencionarlo una vez más". Teodolfo Lagunero, por su parte, sostuvo que "[n]o se puede meter en el mismo saco lo ocurrido en las mal llamadas dos zonas de la Guerra Civil española", subrayando que esta práctica define a "[1]os falsos historiadores" que distorsionan la verdad".

En otras palabras, a pesar de las discrepancias de opinión, la mayoría de los participantes compartió, además del aval mediático, un segundo principio de autoridad: el cientificismo de los historiadores y su método indiscutible de recolección de datos históricos. Si bien la invocación de la autoridad de los historiadores es, en el fondo, un recurso retórico, es obligado señalar la ingenuidad filosófica que encierra la creencia de que los hechos históricos hablen por sí mismos. Supone una regresión a un empirismo más propio del historicismo del siglo XIX o principios del XX que de comienzos del XXI.

Confinada en estos parámetros retóricos, la polémica mediática no fue en modo alguno sensible a la idea bien asentada en medios académicos de que lo que marca las posturas ante el pasado reciente y su violencia no son los hechos históricos de por sí, sino las interpretaciones sobre ellos elaboradas desde dentro de las comunidades hermenéuticas a las que pertenece cada generación de intérpretes (Cabrera, 2001). Menos aún dio oportunidad para plantear la posibilidad — nada revolucionaria, por otra partede que los métodos de los historiadores tengan mucho de arbitrarios y autorreferenciales, como lo son las teorías con las que los expertos relacionan los hechos históricos en un texto, convirtiendo los acontecimientos en datos y dándoles sentido.

El problema de esta actitud es que afecta a cuestiones que van más allá de lo estrictamente académico. Cuando una polémica que es sobre el significado del pasado es disfrazada de discrepancia meramente empírica, y cuyos datos se suponen plena y transparentemente disponibles gracias a la objetividad de la historia académica, la reivindicación de la historia como conocimiento viene, explícita o implícitamente, a despreciar la memoria del ciudadano como mera opinión o emoción subjetivas.

que "[e]s de justicia reconocer el hecho de que la manera como se ha escrito casi toda la Historia impone una parcialidad abrumadora contra la violencia revolucionaria (...). Desde los días de Espartaco a los de Robespierre y hasta hoy mismo, el uso de la fuerza por los oprimidos contra los amos ha sido objeto de casi universal condena". Cf. Moore (1976: 407).

${ }^{10}$ Algo que no deja de ser una constante en la historia europea antes como después de la llamada Revolución Científica (Rorty, 1996). Considérese por ejemplo en este caso el texto "Los sarcasmos, insultos e incoherencias de Fernando Savater," respuesta de Vicenç Navarro a un artículo del filósofo sobre el procesamiento de Garzón. Para Navarro, Savater insultaba directamente a los herederos de las víctimas de la guerra y la represión franquista: "Sería de desear" — concluye — "que los rotativos de mayor difusión del país tuvieran un código de conducta que limitara el número de insultos por artículo". Savater, por su parte, apuntó en otro texto posterior a un supuesto "sectarismo hispánico" que "con su habitual ferocidad inane, fiel a su empeño bifronte de conseguir un país invivible a partir de los despojos de un país en el que se había logrado convivir bastante bien”. 
Este planteamiento reductivo no resulta de recibo. No hay, para empezar, razones intelectuales para semejante menosprecio. La contraposición entre memoria e historia carece de base epistemológica solvente: no es cierto que la historia esté más cerca de una verdad definitiva respecto del pasado porque ni los documentos hablan ni los métodos, las teorías o las categorías de los historiadores son ajenos a las posiciones de los historiadores dentro de culturas. Si hay contraste entre memoria e historia, éste es ante todo retórico, tiene que ver con los juegos de lenguaje que cada una de estas formas de conocimiento del pasado emplea: la historia utiliza una retórica de veracidad basada en la carga documental y en la explicación; la memoria por su parte construye su verdad desde la autoridad del testimonio y la narración (Cruz, 2005). Ambas dimensiones de la construcción del pasado se hallan además recurrentemente entremezcladas en las prácticas discursivas de expertos y no expertos, como ésta polémica deja fácilmente a la vista: cuando estos opinadores y expertos hablan de la Transición, están elaborando un relato a partir de una mezcla indistinguible de datos bibliográficos y recuerdos. En suma, uno puede colocarse frente a estas retóricas como bien pueda o mejor quiera, pero no cabe despreciar la memoria como mero artefacto interpretativo frente a una historia que "cuenta las cosas" tal y como fueron.

A nadie debe por otro lado extrañar que la historia o la memoria sean campos de batalla (Jenkins, 2009). A fin de cuentas, el pasado nos obliga recurrentemente a hablar de él, pero no nos dice cómo hacerlo: pese a los partidarios de la "verdad definitiva", no disponemos de un diccionario extrahumano con el que interpretar de una vez por todas lo sucedido; tan sólo podemos dar sentido a los acontecimientos desde el interior de las comunidades culturales a las que hoy pertenecemos (Kossellek, 1993). El tiempo del pasado es el presente y la diversidad de narraciones sobre unos mismos hechos se funda en las sensibilidades disponibles en cada momento (Virno, 1999). Contemplada así, la verdad del pasado resulta ser tan imperfecta como lo son las identidades de quienes lo interpretamos. Y, lo que es más importante, no es posible controlar el flujo interpretativo que ponen en marcha los ciudadanos al hacerse con una visión del mundo que siempre implica de alguna manera al pasado, y menos aún lo es en un orden pluralista con un mínimo de libertad de expresión.

Al reconocer estos elementales principios epistemológicos, todo el marco de esta polémica sobre los orígenes de la actual legalidad democrática cambia. Lo que se jugó en ella no fue sólo una cuestión de contenido sino ante todo el empeño, por parte de quienes defienden la interpretación definitiva de la historia a partir de unos hechos que hablan por sí mismos, en arrebatar a la ciudadanía el "poder contar", tutelando así el derecho cívico a hablar sobre el pasado. Y es que el poder de contar la verdad última no es algo que, una vez arrogado, se suele desear compartir, pues otorga la capacidad de crear estereotipos con los que, desde la interpretación de hechos pasados, tratar de predefinir la manera en que otros ciudadanos puedan interpretar el presente y anticipar el futuro.

\section{EL SUPUESTO DE LA EXCEPCIONALIDAD ESPAÑOLA EN LA ERA DE LA GLOBALIZACIÓN}

En "Duelo por la República Española", la breve nota escrita por Santos Juliá en EL PAís, el profesor de la UNED no sólo negaba la posibilidad de hacer una distinción moral entre la violencia republicana y la franquista, sino que también advertía contra "la demanda de justicia transicional 35 años después de la muerte de Franco", fenómeno que, acuñando un curioso neologismo, asociaba con "la creciente argentinización de nuestra mirada al pasado".

Tres días antes, y también en El PAís, el filósofo Fernando Savater había publicado "Recuerdos envenenados", una nota elogiosa sobre un libro proyectado del politólogo estadounidense David Rieff, titulado Against Remembrance [Contra el recordar/ conmemorar]. Rieff advierte en su obra del peligro de la memoria histórica o colectiva por hacer "que la historia misma se parezca más que a nada a un arsenal lleno de armas necesarias para mantener las guerras o hacer de la paz algo tenue y frío". "[L]a Historia"-resumía Savater a Rieff — "se ocupa de los sucesos como algo pasado, es decir que ya no está, mientras que la memoria colectiva conmemora el pasado como aún presente - para bien o para mal- y como razón fundamental de las empresas actuales; (...) la memoria colectiva selecciona, sa- 
craliza y mitifica de acuerdo con el narcisismo del grupo y sus ambiciones del momento". Se trata de una posición cercana a la defendida en otros lugares por Juliá; de hecho, es razonable sugerir que las tendencias criticadas por Rieff y Savater son precisamente las que para Juliá constituyen la "argentinización" de la mirada sobre el pasado reciente de España.

Aunque ambas fueran notas breves y tuvieran un carácter más bien informal, su casualidad no logra disimular que contienen toda una filosofía $-y$ toda una política- acerca de dos preguntas cruciales, no sólo para España sino para cualquier país del mundo globalizado: ¿qué postura debe adoptar una democracia, y en particular sus líderes políticos y culturales, ante los acontecimientos violentos de un pasado reciente, y ante los recuerdos de éstos, en particular los de las víctimas de esa violencia?; y ¿hasta qué punto esas posturas de los líderes políticos y culturales han de estar avaladas por normas y criterios (morales, políticos, legales) que transcienden las fronteras de las comunidades culturales y nacionales?

En este sentido resulta interesante que tanto Juliá como Savater se apoyaran en ejemplos extranjeros para criticar lo que consideraban excesos de la memoria. Hasta la fecha, han sido sobre todo las organizaciones y colectivos que reclaman el reconocimiento de las víctimas del franquismo, la exhumación de fosas comunes o la convocatoria de una Comisión de la Verdad, entre otras demandas, los que han venido a invocar las transiciones realizadas en Sudáfrica, Argentina, Chile, Uruguay y otros países, tendiendo así puentes entre el movimiento español por la memoria y la reciente evolución de la legislación internacional en torno a los derechos humanos y la justicia transicional. Para Juliá esos casos extranjeros aportan en cambio una ejemplaridad negativa, mientras que Savater llega a dudar del estatus epistemológico de los derechos humanos. ${ }^{11}$ Puestos a elegir entre una aproximación universalista o particularista a los problemas éticos, políticos y judiciales que plantea la historia reciente española, los dos optan a las claras por lo segundo.

Sorprende este rechazo de la opción universalista en dos intelectuales que, por lo demás, siempre han hecho gala de un perfil moderno y liberal. La explicación hay que buscarla en la aceptación por una parte de la intelligentsia española de una lectura excepcionalista de la historia nacional, y en particular de la relacionada con el pasado reciente y su violencia.

Pues, ¿qué ocurre cuando uno toma distancia de esa interpretación excepcional? Ocurre que todo el debate abierto que venimos analizando se presenta bajo otra luz: el meollo de la cuestión no es ya la implicación cualitativa y cuantitativamente diferente de las instituciones del gobierno republicano o del franquista en las matanzas ocurridas en sus respectivos territorios; ni tampoco si es defendible que la Transición comportó la decisión de no dejar que el pasado determinara el futuro; ni si ciertos abusos y mitificaciones del pasado pudieron ser movilizados para fines abominables. Si se supera la interpretación de la excepcionalidad en la relación de España con su pasado violento, las preguntas que surgen pasan a ser de otra naturaleza: ¿hasta qué punto el Estado puede hacer caso omiso de los tratados internacionales - firmados por España - que se ocupan de la investigación de las desapariciones forzadas y la reparación de los derechos de las víctimas de represión?; y, por extensión, ¿hasta qué punto los intelectuales, académicos o mediáticos, pueden ignorar la evolución de la opinión pública internacional en lo concerniente a cuestiones de memoria histórica, máxime cuando ésta se ha convertido en punto de convergencia de movilizaciones ciudadanas democráticas, como es el caso en España, Argentina, Chile o México?

El apego a unos parámetros de excepcionalidad tiene efectos sobre las opiniones de estos columnistas; les fuerza a ofrecer argumentaciones ad hoc que abren a preguntas incómodas. Así, cuando Savater afirma que "[1]a memoria de los crímenes puede estar justificada en tanto viven quienes los cometieron”, ¿quiere decir que cabía olvidar esos crímenes una vez que los perpetradores hayan muerto?; ¿debemos entonces olvidarnos de una vez por todas de los crímenes cometidos en la Gran Guerra y la Segunda Guerra Mundial, o de los asesinatos concretos perpetrados por un miembro determinado de un

\footnotetext{
${ }^{11}$ Ya en una entrega anterior, de 22 de abril, Savater afirmaba en el mismo periódico: "Confieso que la noción de «crímenes contra la humanidad» me resulta más religiosa o metafísica que jurídica".
} 
grupo terrorista cuando quiera que éste muera? Por su parte, cuando Juliá arremete contra las políticas de memoria como si fueran propias de dictaduras, ¿hay que concluir que acaso son neutrales las representaciones del pasado instituidas por otros medios — por ejemplo, académicos- en una democracia? Qué duda cabe que los políticos se sirven de lecturas interesadas, tergiversadas y mitificadas del pasado para sus fines de movilización, que no siempre son morales. Ahora bien, ¿resulta de recibo reducir todo el fenómeno de la memoria histórica a esos abusos, contrastándola con una noción idealizada de la historia como práctica científica "pura"? La universidad, y en concreto la universidad española, no es precisamente tampoco un espacio exento de presiones y prejuicios políticos e ideológicos (Bermejo, 2009).

En realidad, ni Savater ni Juliá intervinieron en este debate como expertos en ese complejo fenómeno social que es la memoria. Sus reflexiones sobre el tema están para empezar atravesadas por la influencia de sus propios recuerdos. ${ }^{12}$ En su alegato terminan además perdiendo de vista la evidencia más elemental: que una comunidad democrática convive siempre con alguna noción por mínima que sea de un pasado compartido. Esa memoria histórica reside y se moldea en libros de texto, museos, monumentos y placas, novelas, películas, telenovelas, conmemoraciones que son producidos por autores y se difunden sobre públicos que no son expertos. No deja, en fin, de resultar paradójico que estos autores nieguen o demonicen un fenómeno como el de la memoria colectiva cuando lo que implícitamente están haciendo con su intervención pública es, al tratar de influir activamente sobre su actual orientación, reconocer su existencia. Con todo, lo más importante que estos intelectuales mediáticos no tienen en consideración es que, en lo que respecta a los relatos del pasado de la comunidad, una sociedad democrática no puede, a diferencia de una dictadura, ignorar las necesidades y deseos de los ciudadanos, individuales o grupales.

Todo indica que Juliá y Savater arremetieron contra las tendencias jurídicas de la globalización en la medida en éstas han venido a reforzar las lecturas de la Transición Española que denuncian una institucionalización de la impunidad tras la muerte de Franco. La cerrada defensa que hacen de una excepcionalidad para la historia española reciente se muestra así cuestionable en términos no sólo morales sino también deontológicos.

Es probable que aferrarse a la lectura hegemónica sobre los orígenes de la Transición permita evitar temas y preguntas embarazosos, pero si las democracias occidentales modernas pueden mantener alguna pretensión de civilización, ésta reside precisamente en su disposición a hacer frente a su propio pasado, por incómodo que ello sea o por mucho que obligue a cuestionar interpretaciones convencionales durante tiempo asentadas (Judt, 2005). Lo que Juliá llama "la creciente argentinización de nuestra mirada al pasado" no es sino una manera de vilipendiar antes de analizar un fenómeno histórico que debería competerle como experto en historia contemporánea: la creciente internacionalización de la mirada hacia el pasado a partir de claves interpretativas en las que la dimensión de conocimiento se mezcla con cuestiones éticas y políticas. ${ }^{13}$ En estas páginas lo que interesa de ese fenómeno son sus implicaciones, pues merced a él ya no cabe abordar los crímenes de lesa humanidad producidos o arrinconados en la guerra de 1936, la dictadura franquista y la transición democrática como parte de una historia singular de un supuesto pueblo elegido sino como parte de una historia de fronteras supranacionales. Ello debería ser una buena noticia, y no sólo para los que estudian el pasado reciente, pues ¿acaso no se instauró la democracia española justamente para acabar con

\footnotetext{
${ }^{12}$ Savater lo dejó especialmente claro ya en una explícita intervención anterior, al hilo de la demolición de la Cárcel de Carabanchel. Véase “¿El final de la cordura?”, El País, 3 de noviembre de 2008, artículo en el que definió el de la memoria histórica como "el peor cáncer de la España actual”. Juliá ha hecho también abundante uso de sus recuerdos en la mayoría de sus colaboraciones en prensa y artículos académicos sobre la Transición, algunos de ellos ahora recogidos en Juliá (2010).

${ }^{13}$ En ese mismo sentido argumenta Miguel Ángel Rodríguez Arias en una réplica a la nota de Juliá: “cabría denunciar aquí la evidente pretensión de «españolear» el genocidio de Franco en el doble sentido, además, del constante intento de orillar, por todos los medios, la normal vigencia de leyes universales que nunca antes habíamos contestado — para casos fuera de España, claro- y abordar los crímenes franquistas como si se tratase de delitos ordinarios de los que el Estado español pudiese disponer a mejor conveniencia y no de crímenes que por su inhumana naturaleza desbordan la jurisdicción nacional y conciernen a la jurisdicción de todos los Estados del planeta, agreden a todo ser humano en tanto que tal."
} 
la historia excepcional en su trayectoria, urdida con categorías exclusivas y relatos de excepcionalidad?

\section{INTELECTUALES MEDIÁTICOS, HISTORIADORES Y "MEMORIA HISTÓRICA"}

El 25 de mayo de 2010, tres días después de la serie de multitudinarias manifestaciones que, bajo el lema "No a la impunidad del franquismo", cerraron una semana de movilizaciones ciudadanas, se organizó un acto en la Facultad de Ciencias Políticas y Sociología de una universidad pública española cuyo objetivo era poner a intelectuales a dialogar ante estudiantes acerca de los legados no digeridos ni reconocidos del postfranquismo, y más en general acerca de la memoria del traumático siglo XX. La actividad se vio sin embargo deslucida por la ausencia voluntaria de personas del mundo académico con cierto renombre: ningún especialista en la Transición de una larga lista de contactados se mostró dispuesto a debatir públicamente acerca del pasado reciente y nuestra relación con él, respondiendo a preguntas de otros ciudadanos concernidos. ${ }^{14}$

Se trata de un botón de muestra más de cómo el de la memoria ha sido desde sus inicios un tema de opinión pública que no provoca entre los académicos una intervención crítica constructiva a la altura del fenómeno y menos en diálogo con los ciudadanos interesados, concernidos o afectados. Como viene sucediendo al menos desde las movilizaciones contra la segunda guerra de Irak, son más bien otro tipo de figuras públicas - artistas, literatos, actores... - las que hacen acto de presencia en las manifestaciones y páginas de opinión. Escasean en cambio los expertos que, al hilo de la revisión ciudadana del pasado reciente, den valor en su trabajo a las renovaciones producidas en el campo de conocimiento de la memoria. ${ }^{15}$

Esta postura predominante entre los científicos sociales queda reflejada en la contribución de José Juan Toharia a la "escaramuza de papel" que venimos relatando en este artículo. Con una argumentación en clave formalmente sociológica, éste retomó la vieja idea de que "[1]a España del 36 no se agotaba en «dos Españas cainitas»": "junto a ellas, mejor dicho, entre ellas - existía una mayoritaria tercera España que braceó, sin éxito, por evitar el desgarro. No lo logró y quedó finalmente laminada". Para justificar esta opinión el autor ofrecía una interpretación de los datos procedente de una encuesta de la agencia Metroscopia, de la que es director. Éstos parecían avalar que "[e]ntre quienes ahora conforman este país, menos de la mitad dice que, al estallar la guerra, su familia se posicionó con uno de los dos bandos contendientes", de manera que "[1] a mayoría absoluta (57\%) procede (...) de familias que bien pueden ser caracterizadas, en bloque, como integrantes de la Tercera España”.

Además de su extraña consideración de la "familia" como unidad de identificación política (lo cual le permitía clasificar a las familias políticamente divididas como ¡“neutrales”!), el autor no mostró preocupación alguna por establecer una distinción significativa entre estos dos períodos históricos considerados. Para él, que los jóvenes de hoy procedan de "entornos familiares que verosímilmente optaron por un black out total sobre el tema" de la guerra pone de manifiesto "una voluntad de no implicación y de olvido, para [éstos] y, en lo posible, para sus descendientes". Argumentar así sin tener en cuenta

\footnotetext{
14 “99 Segundos One Step Beyond, Transición, Democracia e Impunidad. Nuevas perspectivas generacionales” organizado por la red de profesores e investigadores "La Promotora", con la colaboración de la Asociación para la Recuperación de la Memoria Histórica, la Fundación Contamíname, la Fundación CEPS, la AU Contrapoder, y alumnos de los cursos de Cine y Teatro Político de la Facultad. Contó finalmente con la intervención de los profesores Juan Carlos Monedero, Ramón Cotarelo, Pablo Sánchez León y Enrique Curiel, todos ellos de la facultad de Ciencias Políticas y Sociología de la Complutense. El resto de los invitados que accedieron a participar fueron: el actor Willy Toledo, la escritora Almudena Grandes, el diputado del PSC/PSOE y ponente de la Ley de Memoria Daniel Fernández y el abogado de víctimas de la represión franquista Carlos Slepoy. El guión y dirección del programa corrió a cargo de los profesores de la UCM Ariel Jerez, Pablo Iglesias y Carolina Bescansa y la presentación del profesor Pablo Iglesias. Hay que tener en cuenta que en la Facultad de Ciencias Políticas de la Universidad Complutense ejercen como profesores e investigadores una parte importante de los autores de las visiones convencionales dominantes sobre la transición española postfranquista. Véase la convocatoria del acto en promotoracomplutense.blospot.com.

${ }^{15}$ Dos excepciones son Reyes Mate (2005) y Manuel Cruz (2005), si bien estos dos autores están al margen de las movilizaciones sociales que han tenido lugar en España.
} 
la larga dictadura y su tiempo de silencio impuesto, especialmente entre quienes pudieran haber tenido simpatías por el bando republicano, es una manera burda de naturalizar el pasado creando sujetos estereotipados a partir de las convenciones del presente. Por suerte en esta ocasión, ha habido intervenciones posteriores de otros sociólogos en las que manifiestan su escepticismo ante el rigor metodológico y conceptual del autor, el cual se vio obligado a aclarar a Carlos Carnicero que su concepto de "Tercera España" "no e[ra] sino un recurso retórico para cuestionar la idea de las «dos Españas», es decir, de un país irremediable y radicalmente partido en dos".

Con la inclusión de científicos sociales, la polémica que hemos analizado permite plantear que, en conjunto, el tema de la memoria está poniendo en el punto de mira a esos que antes solíamos llamar de un modo un tanto impreciso, intelectuales. Se nos ha querido convencer de que el final de la Guerra Fría debía serlo también de la figura social del intelectual. En realidad, en España el asunto tiene otros orígenes, que nos acercan a la Transición y a una singular defección de los intelectuales. Muchos de ellos no es que hayan abandonado la defensa de líneas partidistas e ideológicas impuestas, sino que con el tiempo han dejado, salvo contadas excepciones, de implicarse como ciudadanos en asuntos de actualidad y salud democrática.

Este fenómeno de largo plazo coexiste paradójicamente con un creciente encumbramiento mediático de determinadas figuras académicas elevadas a la posición de formadores de opinión en régimen de oligopolio. La crisis del intelectual que se nos ha querido vender encubre en realidad una operación distinta, que consiste en denigrar al intelectual comprometido por adscribirse "ideológicamente" y al tiempo imponer una minoría de profesionales y académicos por la supuesta garantía que ofrecen como expertos desapasionados. Pero como deja clara la polémica que hemos presentado, estas personas no están ejerciendo ninguna labor pedagógica ni de hecho están hablando como especialistas. Su opinión no se funda en unos méritos académicos que apenas informan su actividad como publicistas en éste o aquél grupo mediático, de manera que no ha de verse como más valiosa que la de cualquier ciudadano sin especialización.

El "nuevo intelectual" reticente a ese nombre reúne de hecho lo peor del viejo intelectual ideológico de la izquierda y del mandarín de la cultura de siempre: habla de un lado ex cathedra de lo que no siempre conoce demasiado bien, y cuando puede ofrecer su conocimiento experto, lo hace sin disposición alguna al diálogo, ni con colegas académicos ni con ciudadanos legos, aceptando como único interlocutor válido al tertuliano o columnista avalado por un capital más social que intelectual.

Los historiadores profesionales se encuentran en una encrucijada excepcional a este respecto. Abundan de un lado las voces que reclaman que la opinión pública acerca del pasado reciente se deje exclusivamente en manos de especialistas, como si los relatos que elaboran éstos no estuvieran marcados por sus posturas acerca de asuntos del presente. ${ }^{16} \mathrm{De}$ otro, es de las filas de los historiadores de donde se están reclutando formadores de opinión que encarnan el mayor divorcio entre la condición de experto y la intervención mediática sobre todo tipo de temas de actualidad.

Esta encrucijada ha quedado también registrada en el marco de la polémica que nos ocupa. Mientras ésta se producía en la prensa, el Instituto Ortega y Gasset —que acoge a bastantes de los más renombrados historiadores mediáticos_-, invitó a dar una conferencia a la historiadora Margaret Macmillan, Decana del St. Anthony's College de la Universidad de Oxford. Al hilo de ella concedió una entrevista en la que remarcó que "hay grandes oportunidades de entrar en el debate público que los historiadores rechazan cada vez más", criticando la tendencia entre algunos colegas a ceñirse a la discusión de temas historiográficos, "dando la espalda al gran público" ${ }^{17}$ Tras rechazar que la historia sea "demasiado compleja como para hacerla accesible al público general", sentenció con rotundidad que los historiadores deben intervenir en el debate político, no sim-

\footnotetext{
${ }^{16}$ Un ejemplo reciente, a cargo de Antonio Muñoz Molina, quien afirma que el hablar de la Guerra Civil no corresponde "ni a los políticos ni a los jueces, sino a los historiadores". Véase http://www.abc.es/agencias/noticia.asp?noticia=473633, Noticia de agencia EFE, Roma, 02-VIII-2010.

${ }^{17}$ La entrevista, realizada por Julio Crespo McLennan, profesor del Instituto de Investigación Ortega y Gasset, tuvo lugar el 15 de junio de 2010, y fue subida a la página web de la institución (http://www.ortegaygasset.edu/noticia_ampliada.asp?id_s=78\&y=2\&id_
} 
plemente abstenerse. Somos ciudadanos después de todo. Sobre todo tenemos la obligación de intervenir en política cuando la historia se está utilizando de una forma falaz. Debemos defender la verdad y denunciar la manipulación con fines políticos allí donde se dé. Luego, si un historiador decide dar el salto a la política, creo que esto es perfectamente legítimo. Ha habido bastantes casos de historiadores en política, tanto en Canadá como en el Reino Unido.

La autora abogó pues expresamente por que, en nombre de una "verdad" histórica que ha de imponerse públicamente, el historiador no sólo goce de una autoridad exclusiva en temas relacionados con el pasado sino que además se implique activamente en cuestiones bien alejadas de sus temas de estudio. Implícitamente, su enfoque viene a mostrar una vez más la disposición de algunos historiadores a escamotear a los ciudadanos el derecho a contribuir a la construcción colectiva del recuerdo, actitud habitualmente disfrazada bajo la apariencia de un debate entre memoria e historia como formas de conocimiento.

Que ésta no es una postura marginal puede verse en una última iniciativa académica desarrollada en el contexto de la polémica que hemos analizado. En la primavera de 2010, el Consejo Superior de Investigaciones Científicas organizó un evento en el que supuestamente una serie de académicos iban a tratar sobre las relaciones entre historia y memoria ante un público igualmente experto. Pues bien, en representación del área intelectual de la "memoria" a quien se invitó fue a una periodista del diario El País que ha venido cubriendo las noticias de exhumaciones; por el lado de la "historia", participaron en cambio no uno sino dos historiadores que trataron de establecer desde criterios normativos las diferencias entre las dos supuestas esferas de conocimiento. ${ }^{18}$

Más preocupante aún fue con todo la intervención de parte del público: uno de los participantes llegó a afirmar que "se trata de resolver un problema de justicia, no es un problema de historia. Un historiador al pie de las fosas no cumple ningún papel". Se trata de una muestra evidente del escaso nivel que alcanza en medios académicos el debate sobre las implicaciones públicas del conocimiento, pues si las exhumaciones son posibles es a menudo gracias a que se recaban datos típicos del historiador, de la misma manera que muchas de las evidencias que se obtienen en las exhumaciones son relevantes desde un punto de vista historiográfico. La postura se vuelve aún más inexplicable si se tiene en cuenta que las exhumaciones de civiles asesinados impunemente después del golpe de 1936 y de la victoria militar franquista acogen en cambio una amplia variedad de especialistas y técnicos, desde arqueólogos a psicólogos, que ofrecen su conocimiento a menudo voluntariamente para llevar a buen puerto una actividad en la que no se ventilan sólo cuestiones de conocimiento, sino también de justicia y de mejora en la convivencia entre ciudadanos. ${ }^{19}$ Pero lo realmente sintomático de que estamos ante una encrucijada deontológica es que el tipo de opinión "autorizada" como la que acabamos de recoger más arriba coincide como hemos visto con otras voces que están instando a los historiadores a implicarse activamente en la esfera pública como formadores de la opinión de sus conciudadanos.

\section{DE PARAÍSOS E INFIERNOS}

Con este recorrido por un típico debate público a la española esperamos haber llamado la atención sobre cuestiones que son, unas intra-académicas y otras extraacadémicas. Mientras el debate público sobre la Guerra Civil, la Dictadura Franquista y la Transición Democrática no recoja reflexiones más rigurosas sobre el recuerdo como actividad social,

noticia $=507 \&$ inc_noticia $=2 \#)$, desde donde se distribuyó por toda la ciberprensa en forma de una nota que destacaba la afirmación de esta profesional para la cual "el término memoria histórica suena a [sic] contradictorio" (i.e., http://www.elimparcial.es/cultura/ margaret-macmillan-historiadora-el-trmino-memoria-histrica-suena-a-contradictorio-65598.html).

${ }^{18}$ Manzano y Pérez Garzón (2010). En expresión del pluralismo interpretativo que anima a los promotores del encuentro y el libro, los dos ponentes historiadores invitados ¡son colaboradores en proyectos de investigación sobre producción historiográfica y memorística!, habiendo incluso firmado juntos artículos, según se reconoce en la nota biográfica que contiene el propio libro. El libro, que paradójicamente forma parte de una serie titulada "Debates científicos" y se abre con una presentación a cargo del presidente del CSIC tiene pretensiones claras de llegar al gran público, de ahí que sea una coedición entre el CSIC y la editorial La Catarata.

${ }^{19}$ Un ejemplo pionero de resultados de esta sinergia entre movilización ciudadana y trabajo especializado voluntario, en F. Etxebarría et al. (2002). 
seguirá lastrado como hasta ahora por presupuestos espurios, como la contraposición poco elaborada entre historia y memoria, la confusión entre memoria colectiva y régimen institucional de memoria, o entre éste y la imposición de una política excluyente acerca del recuerdo del pasado reciente. Los temas de la memoria son tan múltiples y complejos que reclaman una cooperación de expertos con enfoques plurales que se muestren además dispuestos a reconocer que los ciudadanos no expertos ofrecen aportes cruciales en la elaboración de narrativas que dan sentido al pasado, especialmente cuando se trata de sucesos conflictivos o traumáticos.

En efecto, en asuntos como éstos, una cultura democrática se mide por su capacidad de desplegar canales de expresión, participación e intercambio que reflejen la variedad de fuentes legítimas de conocimiento acerca del pasado, evitando que una minoría de supuestos expertos y opinadores con notoriedad mediática escamoteen a los ciudadanos el derecho a participar en la construcción colectiva del recuerdo, tan esencial para la calidad de vida ciudadana. Pues lo que se dirime en los debates sobre historia y memoria es en realidad quién tiene el poder de contar el pasado a sus conciudadanos; y en ello va el definir también fenómenos del presente, entre ellos el dar nombre a fenómenos sociales emergentes. En el caso de la polémica concreta que hemos analizado, lo que había detrás de algunas de las supuestas interpretaciones históricas era el intento de desacreditar el movimiento social por la memoria, identificándolo con quienes se consideran "nietos de la guerra" cuando debieran verse ante todo como "hijos de la transición".

Que una gran parte de los ciudadanos hayamos sido testigos pasivos de esa manipulación mediática, incluso que tengamos que convivir con quienes siguen instando a que el conocimiento del pasado es propiedad exclusiva de los historiadores, son malas noticias. Pero aquí viene la buena: la incontenible presencia en la esfera pública de una opinión organizada y movilizada, defensora de su derecho a "po- der contar" la transición y la guerra de 1936, pone de manifiesto algo que señala la escritora nigeriana Chimamanda Adichie al afirmar que, cuando advertimos la inviabilidad de la historia única, "recuperamos una suerte de paraíso perdido". ${ }^{20}$

Ese paraíso no es pues el de la nostalgia por unos tiempos pasados mitificados sino el de la libertad de interpretación del mundo por parte de los ciudadanos, algo que se garantiza cada vez que se termina con algún monopolio en términos de conocimiento. Ahora bien, para que dicha garantía resulte duradera, sería recomendable que esa nueva hornada de intérpretes cívicos del pasado superara la tentación de recaer en los cantos de sirena de la historia definitiva y tratara de seleccionar además relatos sobre el pasado que se reivindiquen de la igualdad inherente a la condición ciudadana. ${ }^{21}$ Evitar el descenso a los infiernos de la clausura interpretativa no es algo que se logre a voluntad, sino que requiere del concurso de un tipo de pensadores públicos dispuestos a interaccionar con la demanda de conocimiento que surge de la sociedad civil. Tal y como sucede en Argentina, por ejemplo, donde la exigencia social de investigación, justicia y reparación ha encontrado una respuesta en el interior del mundo académico beneficiosa para el aumento de la conciencia cívica y del conocimiento socialmente relevante (Vinyes, 2010, e Izquierdo Martín, 2009).

Si queremos evitar ser desposeídos de nuestra dignidad como ciudadanos estamos convocados a luchar por la democratización del conocimiento histórico, eso que Rafael del Águila llamó el avance de la "remembranza" (Del Águila, 2006) y que reclama la concurrencia de muchas voces para alcanzar algún consenso que, aunque temporal, demuestre que hemos recuperado nuestro poder para contar. Sólo entonces la "guerra de papel" sobre la Guerra de 1936 y la Transición será cosa del pasado, al pasar por fin a ser objeto de diálogo cívico, cosa que su última batalla mediática no puede decirse que haya ocurrido.

\footnotetext{
${ }^{20}$ La conferencia puede seguirse en http://www.ted.com/talks/lang/spa/chimamanda_adichie_the_danger_of_a_single_story.html

${ }^{21}$ Según este criterio de selección, cabría pensar si son pertinentes los relatos sobre la violencia revolucionaria de los años 30 que omiten malintencionadamente la desigualdad socioeconómica que contribuyó a desatar aquella violencia, o las narraciones que siguen diferenciando entre víctimas del terrorismo - léase franquista o de ETA—, echando aún más tierra sobre las vergonzantes fosas comunes que jalonan España.16 Un ejemplo reciente, a cargo de Antonio Muñoz Molina, quien afirma que el hablar de la Guerra Civil no corresponde "ni a los políticos ni a los jueces, sino a los historiadores". Véase http://www.abc.es/agencias/noticia. asp?noticia=473633, Noticia de agencia EFE, Roma, 02-VIII-2010.
} 


\section{REFERENCIAS}

\section{De la polémica (por orden cronológico)}

Fernando SaVater, "Las sectas en pie de guerra", El País, 22-04-2010.

Joaquín Leguina, "Enterrar a los muertos", El PAís, 24-04-2010.

Almudena GrandES, "La condición miserable", EPS, 09-05-2010.

Vicenç NAVArro, "Los sarcasmos, insultos e incoherencias de Fernando Savater", vnavarro.org, 10-05-2010.

Teodolfo Lagunero, "Enterrar a los asesinados por los fascistas", El País, 29-05-2010.

Javier Cercas, "La puñetera verdad", El PAís, 06-06-2010.

Joaquín Leguina, "Y vuelta la burra al trigo", El PAís, 10-06-2010.

Jorge M. Reverte, "Los muertos de todos", El País, 18-06-2010.

Fernando SAVATER, "Recuerdos envenenados", El PAís, 22-06-2010.

Santos Juliá, "Duelo por la República española”, El PAís, 25-06-2010.

Gregorio Marañón, "La insobornable verdad", El País, 28-09-2010

Josep Fontana, "Julio de 1936", Público, 29-06-2010.

Javier CERCAS, “Respuesta a Gregorio Marañón”, El PAís, 30-06-2010.

Gregorio Marañón Bertrán de Lis, "Respuesta a Javier Cercas", El País, 03-07-2010.

José Juan Toharia, “La Tercera España, 74 años después”, El País, 18-07-2010.

Carlos Carnicero, "La tercera España", El País, 21-07-2010.

José Juan Toharia, "Respuesta a Carnicero", El País, 22-07-2010.

Aitor CARR, "Estupefacción", El PAís, 23-07-2010.

Pío Moa, "Santos Juliá va enterándose", LiberTad Digital, 28-06-2010.

Vicenç NaVArro, "La oposición de Santos Juliá a la Ley de Memoria", EL PLURAL.COM, 26-07-2010. http://www. vnavarro.org/?p=4507

Floren DimAs, "Santos Juliá y los historiadores casadistas", TERCERA INFORMACIÓN, 04-07-2010. http://www. foroporlamemoria.info/2010/07/santos-julia-y-los-historiadores-casadistas/

Pedro A. García Bilbao, "El amargo fruto de la impunidad", CiUdADANOS POR LA REPÚBlICA, 05-07-2010. http://www. tercerainformacion.es/spip.php?article16949

Miguel Ángel Rodríguez ARIAS, “¿Por qué lo llaman “argentinizar” la transición cuando lo que quieren es terminar de “españolizar” el genocidio de Franco?”, REBELIÓN, 19-07-2010. http://www.rebelion.org/noticia.php?id=109935

Carlota Leret O'Neill, “La nostalgia del franquismo. Respuesta a Santos Juliá. Carta a El País”, DeSPAGE 3-07-2010. http://www.nodo50.org/despage/

Pedro L. Angosto, "Santos Juliá en el limbo de los justos", NUEVA TRIBUNA, 22-07-2010 (http://www.nuevatribuna.es/ noticia/37700/OPINI\%C3\%93N/retos-educaci\%C3\%B3n-p\%C3\%BAblica-madrile\%C3\%B1a.html.).

\section{Otras referencias}

Bermejo, José Carlos (2009), La fábrica de la ignorancia: la universidad del "como si”, Madrid, Akal.

CABrera, Miguel Ángel (2001), Historia, lenguaje y teoría de la sociedad, Valencia, Cátedra.

CASAnova, Julián (2007), "Después de tanta memoria...", El PAís, 20 de septiembre.

Castro, Javier y Saúl Martínez (2008), "Monólogo. Educación, tradición y comunicación en la historiografía académica española”, en Pablo Sánchez León y Jesús Izquierdo Martín (eds.), El fin de los historiadores. Pensar históricamente en el siglo XX. Madrid, Siglo XXI.

Cercas, Javier (2009), Anatomía de un instante, Barcelona, Mondadori.

CRUZ, Manuel (2005), Las malas pasadas del pasado: identidad, responsabilidad, historia. Barcelona, Anagrama

Del Águila, Rafael (2006), "Desmemoria y rememoración: la guerra y el franquismo hoy", Historia y Política, 16: 183-208.

EtXebarRía, Francisco (2002), “Antropología del pasado reciente: una fosa común de la Guerra Civil Española en Priaranza del Bierzo (León)”, en Assumpció Malgossa et al. (coords.), Antropología y biodiversidad, 1: 431-446.

Espinosa Maestre, Francisco (2005), El fenómeno revisionista o los fantasmas de la derecha, Badajoz, Del Oeste ediciones.

FABER, Sebastiaan (2007), “The Debate about Spain's Past and the Crisis of Academic Legitimacy: The Case of Santos Juliá", The Colorado Review of Hispanic Studies 5: 165-90. 
HaYnes, M. (1998), “Movimiento y violencia popular en la Revolución Rusa” (www.enlucha.org).

Izquierdo Martín, Jesús y Pablo Sánchez León (2006), La guerra que nos han contado. 1936 y nosotros, Madrid, Alianza.

IzQUiERdo Martín, Jesús (2009), "Cuando la distancia no importa. Memoria e historia en América Latina y España", en C. Romero y A. Sabio (coords.), Universo de microcosmos, Actas del VI Congreso de Historia Local, Zaragoza, Institución "Fernando el Católico" y Prensas Universitarias de Zaragoza (CSIC): 39-46.

JENKIns, Keith (2009), Repensar la historia, Siglo XXI.

JudT, Tony (2005), Postwar. A History of Europe since 1945, Nueva York, Penguin.

Juliá, Santos (2003a), "Últimas noticias de la Guerra Civil", Revista de Libros, 81: 6-8.

JuliÁ, Santos (2003b), "Echar al olvido: memoria y amnistía en la transición”, Claves de Razón Práctica, 129: 14-25.

Julí́, Santos (2006 a), "Bajo el imperio de la memoria", Revista de Occidente, 302-303: 7-20.

Juliá, Santos (2006b), "Trampas de la memoria”, El PAís, 14-10-2006.

JuliÁ, Santos (2009), "El retorno del pasado al debate parlamentario (1996-2003), Alcores, 7: 231-256.

Julí́, Santos (2010), Hoy no es ayer. Reflexiones sobre el siglo XX en España, Madrid, RBA ediciones.

Koselleck, Reinhart (1993), "Compromiso con la situación y temporalidad", en Futuro pasado. Por una semántica de los tiempos históricos, Barcelona, Paidós: 173-201.

Ledesma, José Luis (2009), "Del pasado oculto a un pasado omnipresente: las violencias en la Guerra Civil y la historiografía reciente", Jerónimo Zurita, 84: 163-188.

Manzano Moreno, Eduardo y Juan Sisinio Pérez Garzón (eds.) (2010), Memoria histórica, Madrid, CSIC-La Catarata.

Mate, Reyes (2009), La herencia del olvido, Madrid, Errata Naturae.

MOORE, Barrington, Jr. (1976), Los origenes sociales de la dictadura y de la democracia: el señor y el campesino en la formación del mundo moderno, Barcelona, Península.

Moradiellos, Enrique (2007), "Revisión histórica crítica y revisionismo presentista: el caso español”, Temas para el debate, 147: 23-28.

Palti, Elías (2008), "Pensar históricamente en una era postsecular o el fin de los historiadores después del fin de la historia", en Pablo Sánchez León y Jesús Izquierdo Martín (eds.), El fin de los historiadores. Pensar históricamente en el siglo XXI, Madrid, Siglo XXI.

ReIG TAPIA, Alberto (2006), Anti-Moa, Madrid, Ediciones B.

RoRTY, Richard (1996), Objetividad, relativismo y verdad, Buenos Aires, Paidós.

SÁNCHEZ Soler, Mariano (2010), La transición sangrienta. Una historia violenta del proceso democrático en España (1975-1983), Barcelona, Península.

Serna, Justo (2006-2007), "Las iluminaciones de Pío Moa. El revisionismo antirrepublicano", Pasajes de Historia Contemporánea, 21-22: 99-108.

Silva, Emilio y Santiago Macías (2003), Las fosas de Franco. Los republicanos que el dictador dejó en las cunetas, Madrid, Temas de Hoy.

VINYES, Ricard (2009), "La memoria del Estado", en El estado y la memoria. Gobiernos y ciudadanos frente a los traumas de la historia, Barcelona, RBA: 23-66.

VIRno, Paolo (1999), El recuerdo del presente. Ensayo sobre el tiempo histórico, Barcelona, Paidós. 